Management, 31, 99-119), and 21\% of freshwater wetlands have been lost in China alone (Nature, 435, 1179-1186). Large-scale reclamation projects, such as the $400 \mathrm{~km}^{2}$ Saemangeum project in the Republic of Korea, have swiftly transformed many coastlines along the Flyway to urban, agricultural and industrial land.

Despite the strong focus on habitat loss as a cause of rising extinction risk in the Flyway, delegates also identified pollution, human disturbance and hunting as important threats to migratory species. Some estimates put the number of migratory birds captured and killed annually for human consumption in the Flyway at 60,000, with such harvesting being particularly prevalent in Indonesia and Myanmar. Aquaculture directly competes with migratory bird habitat, and production in Asia accounts for c. $89 \%$ of the global market (FAO, 2012, The State of World Fisheries and Aquaculture, http://www.fao.org/docrep/016/i2727e/ i2727eoo.htm). Declining sediment outputs from Asia's major rivers have reduced the accretion of tidal flats in recent decades; the Yellow River, for example, is now one of the most heavily affected waterways in the world (Nature Geoscience, 2, 681-686).

Although the scale of the task is enormous, progress is being made to conserve key sites along the Flyway. During the meeting Indonesia announced that Sembilang National Park would become the 108th Flyway Network Site listed by the Partnership, signalling a collective commitment to conserving important sites for migratory species. While the Partnership still lacks a formal conservation prioritization, many of the listed sites are implementing conservation management. The sharing of expertise across the Flyway has enabled the identification and control of specific threats, such as the invasion of introduced plant species (e.g. Sonneratia caseolaris) at Mai Po Inner Deep Bay in Hong Kong. Recently the IUCN commissioned a situation analysis of the patterns and drivers of intertidal habitat loss in the Flyway. The report highlights the risk to humanity and biodiversity of a continued trajectory of coastal habitat loss in the region and recommended a full scale ecosystem service analysis. The topic will be raised at the World Conservation Congress to be held in Korea in September 2012.

We remain deeply concerned at the scale and rate of coastal habitat loss throughout the East Asian-Australasian Flyway. But with a diverse group of members and technical advisers, and with the goal of continued collaboration between partners, the Partnership is working for conservation of migratory birds and their habitats in the Flyway.

Nicholas J. MurRay and Richard A. FulLER School of Biological Sciences, The University of Queensland, St Lucia, Queensland Australia, and CSIRO Climate Adaptation Flagship and CSIRO Ecosystem Sciences, Dutton Park, Queensland, Australia E-mail nick.murray@uq.edu.au

\section{India refines tiger monitoring protocols}

India is currently thought to hold $50 \%$ of wild tigers. These tiger populations, however, are distributed over vast, fragmented forest blocks that cover 100,000-200,000 $\mathrm{km}^{2}$. Of this habitat only $25 \%$ is in protected Tiger Reserves. Consequently, monitoring tiger populations has been a challenge. After the failure of the traditional pug-mark census practice based on total track counts was recognized by the Government in 2005, India's National Tiger Conservation Authority (NTCA) made efforts to develop newer methodologies to monitor tiger populations more reliably.

A global biogeographical analysis led by Wildlife Conservation Society (WCS) scientists (Walston et al., 2010, PLoS Biol, 8(9), e1000485) showed that about $70 \%$ of wild tigers, including cubs and transients, are now concentrated in only $6 \%$ of the remaining 1.1 million $\mathrm{km}^{2}$ habitat, thus highlighting the need for intensive annual monitoring of these source populations. The NTCA has been working with WCS scientist Ullas Karanth to refine monitoring methods for key tiger source populations, based on research and experience gained from his long-term efforts in the state of Karnataka. In the Malenad-Mysore landscape in Karnataka, working in collaboration with the State Forest Department, Karanth and his team have been monitoring five tiger source populations in $4,000 \mathrm{~km}^{2}$ for over a decade, using advanced photographic capturerecapture methods to generate reliable estimates of tiger population size and density, and survival, recruitment and dispersal rates (Karanth et al., 2011, Science, 332-791). These data show that tiger densities are high (10-15 tigers per $100 \mathrm{~km}^{2}$ ) in well-established reserves such as Nagarahole and Bandipur, and are increasing (3-6 tigers per $\left.100 \mathrm{~km}^{2}\right)$ in two other reserves in response to recent conservation measures.

Refined tiger monitoring protocols under Phase IV of the national tiger estimation announced recently by NTCA (http://projecttiger.nic.in/whtsnew/Protocol_Phase_ IV_Monitoring_r.pdf) specify rigorous new monitoring standards, such as a minimum sampling area $>400 \mathrm{~km}^{2}$, a trapping intensity of 1,000 traps per $100 \mathrm{~km}^{2}$ and a closure period of 45-60 days. These are also linked to a national database of tiger camera-trap photographs being set up in collaboration with scientific institutions. It is expected that these refinements to the monitoring protocols will lead eventually to rigorous tracking of tiger numbers in all key source populations in India, thus enabling authorities to manage wild tiger populations more effectively.

N. SAMBA KUMAR and PRERNA SINGH BINDRA Wildife Conservation Society-India Program, Centre for Wildlife Studies, 1669, 31st Cross, 16th Main, Banashankari 2nd Stage, Bengalooru560 070, India

E-mailsamba.wcs@gmail.com 